\title{
Interactive Therapy with Instrumented Footwear
}

\author{
Joseph A. Paradiso, Stacy J. Morris, Ari Y. Benbasat, Erik Asmussen \\ Responsive Environments Group \\ MIT Media Laboratory \\ Cambridge, MA USA 02139 \\ \{joep,sjm,ayb,asmussen\}@media.mit.edu
}

\begin{abstract}
Musical feedback can aid in learning to move properly, for example in physical therapy, sports medicine, or training. By appropriately instrumenting the body to detect the correct motion (or the motion to be avoided), and mapping its characteristics causally onto an interactive musical stream, a patient can, in certain cases, be discouraged from making the incorrect motion and encouraged to move properly. We describe a heavily instrumented pair of shoes that were developed to function as a wearable gait laboratory, and overview some of the initial work performed using these shoes for real-time interactive therapy based exploiting musical feedback.
\end{abstract}

\section{Author Keywords}

Interactive therapy, biofeedback, musical mapping, shoe interfaces, wireless sensing.

ACM Classification Keywords

H.5.2 User Interfaces, H.5.5 Sound and Music Computing

\section{INTRODUCTION}

Although Music Therapy is an established field of clinical practice [1], most treatment involves fairly conventional musical dialog; e.g., patients playing musical instruments or listening to particular types of music. As sensors can now respond to a variety of physically and biologically generated signals, and computers are able to map these stimuli onto an infinite variety of musical responses in real time, interactive music is becoming a therapeutic tool.

Well before computers augmented the generation and composition of music, researchers were exploring the application of electronic sound to biofeedback. Using analog synthesizers and later also minicomputers, pioneers such as David Rosenboom and Richard Teitelbaum were producing electronic music from brainwaves, heart rates, EMGs, skin conductivity, and other bioelectric signals for experiments in real-time musical biofeedback dating to the

\footnotetext{
COPYRIGHT IS HELD BY THE AUTHOR/OWNER(S). CHI 2004, APRIL 24-29, 2004, VIENNA, AUSTRIA. ACM 1-58113-703-6/04/0004.
}

late 1960's [2]. Although the field is rife with new-age exploitation, credible projects in relaxation therapy [e.g., 3], (interactive music and visuals produced to damp sensed parasympathetic parameters) continue to the present day. Interactive music has also been used for therapy with mentally disabled and autistic children [e.g., 4], where simple causal mappings between free gesture and sound can encourage even extremely withdrawn patients to move about enthusiastically after several treatment sessions. Although causal motion-to-music mappings are well established for artists working in the area of interactive dance [5], there is currently only limited activity investigating interactive music for sports training and physical therapy. In sports, body-worn sensors are becoming more common, but audio feedback is generally limited to a simple beep when heart rate limits are exceeded or a talking virtual coach who critiques your swing [6]. A more sophisticated musical stream could be capable of transferring information in a prompt, intuitive fashion and in a potentially more pleasant format. Now that wireless, wearable sensor systems are becoming increasingly capable and synthesized, interactive music can be generated in a common PDA, rapid development can be expected in the area of portable, real-time musical feedback for various aspects of physical therapy, training, and exercise.

\section{THE GAIT SHOE AND WIRELESS SENSOR STACK}

In a prior project dating from 1997, we instrumented a pair of dancer's shoes [7], enabling them to become sophisticated music controllers. Each was equipped with a wireless sensor package measuring 16 disparate degrees of freedom. The resulting data was used to produce real-time music that intricately followed a dancer's movements in improvisational performances. This project evolved into a collaboration with the Biomotion Laboratory at the Massachusetts General Hospital that aimed to produce a compact, wearable platform that collected enough data to subsume some aspects of a gait analysis facility sophisticated installations with expensive motion tracking and force-measuring capability. Termed the "Gait Shoe," [8] it measures many parameters (up to 18 per foot) that can be of clinical interest. These include continuous pressure beneath the heel (medially and laterally) and behind the toes (under both the first and fifth metatarsal heads), piezoelectric strips for prompt indication of toe-off and heel-strike, insole bend, ankle bend, and 3 axes of 

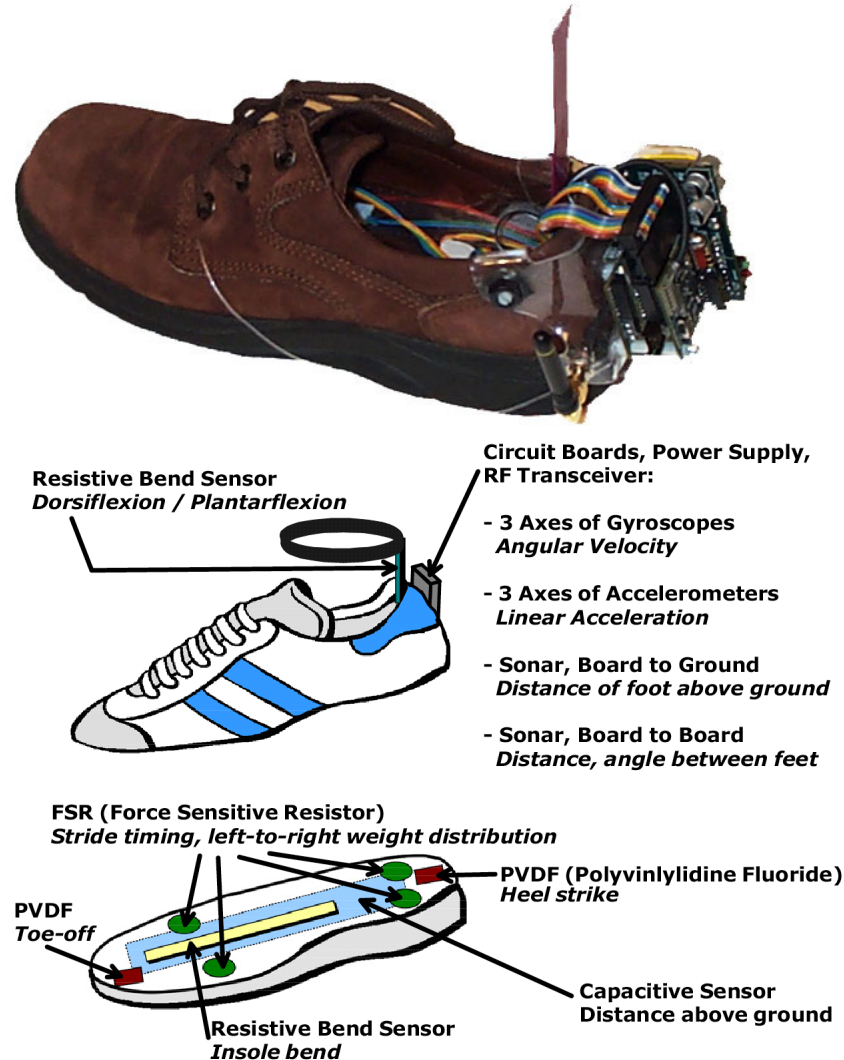

Figure 1: Working Gait Shoe (top) \& sensor layout (bottom)

acceleration and 3 axes of rotational rate behind the heel. A pair of capacitive proximity-sensing electrodes measure the height of the shoe from the floor at two locations, a sonar is able to determine the relative angle and displacement between the feet, and another sonar is able to measure the distance to the ground along the line of the heel.

All measurements are taken by the "Sensor Stack" [9], a compact configurable wireless sensor cluster that we have recently designed, mounted behind the shoe's heel. The Stack's circuit boards can be layered and connected as needed to acquire a desired suite of measurements; each Stack layer is dedicated to a particular function (e.g., 6-axis IMU, tactile measurements, sonar). A processor/RF Stack card acquires and serializes all data, then transmits at 115 kbits/sec via a simple TDMA scheme, allowing full state updates at $75 \mathrm{~Hz}$ per shoe. The system attaches to a normal shoe via a removable insole and clip-on Stack module (seen in Fig. 1). The system weighs under $300 \mathrm{~g}$, including a 9volt battery that lasts for over 3 hours of continuous use.

\section{MUSICAL FEEDBACK EXPERIMENTS}

Although most of our work involves extracting clinicallyrelevant parameters from the dense stream of shoe data [8], we have started exploring use of the Gait Shoe in real-time musical feedback therapy. Our initial work has focussed on gait in patients with Parkinson's disease, who may suffer from a chronically stunted walk and can spontaneously break into a slow shuffling called festination. Research indicates that Parkinsonian gait improves when patients hear strong rhythmic cues from a metronome [10] or music [11]. These studies are passive, however, as the audio is independent of the patient's activity.

We have written an interactive musical environment for the gait shoe in the MAX graphical programming language that easily allows the sensor signals to be algorithmically combined and processed, then coupled into a wide range of parameters that modify sequenced music in real time [12]. In our first applications, we derived gait rhythm and quality by looking at the load transfer between the front and back pair of insole pressure sensors. When we detected the onset of significant gait arrhythmia or shuffling, a loud metronome click was produced to cue the patient back to a steady pace. Subsequent trials introduced ambient music, continually providing subtle rhythmic cues. When gait defects were detected, the music became less melodic and strongly rhythmic, encouraging the wearer to walk at pace, at which point the pedestrian background music would resume. In this way, the music didn't disappear; rather the wearer was rewarded with the return of a pleasant sonic backdrop when the gait normalized. We have constructed other environments to explore interactive physical therapy, which can be very useful to patients while recovering from an injury, when their movements are biased more to regulating immediate pain rather than avoiding further injury. These include preventing over-pronation or oversupination (when the dynamic foot load is biased more to one side or the other) and regulating the maximum distributed plantar pressure. Upon detecting a pronating or supinating gait, the musical stream is altered in proportion to the condition's severity - i.e., the key gradually modulates from major to minor, then progressively becomes dissonant. For pressure, we are exploring more metaphorical rules, e.g., the music becomes "heavier" (stronger, more aggressive voicings, etc.) when maximum pressure is exceeded. In this way, multiple feedback dimensions may be simultaneously expressed by superimposing different modulation rules.

We have developed these environments with normal subjects, and are now applying to work with actual patients.

\section{ACKNOWLEDGEMENTS}

We acknowledge the support of the Things That Think Consortium, CIMIT, and other sponsors of the MIT Media $\mathrm{Lab}$ and thank our collaborators at the Mass General Hospital's Biomotion Laboratory, especially Donna Scarborough and Dr. David Krebs.

\section{REFERENCES}

1. Wigram, T., Nygaard Pedersen, I., Ole Bonde, L. A Comprehensive Guide to Music Therapy: Theory, Clinical Practice, Research and Training, Jessica Kingsley Publishers, London, England (2003).

2. Rosenboom, D. (ed.), Biofeedback and the Arts: Results of Early Experiments, Vancouver: A.R.C. Publications (1976). 
3. Gromala, D., et al, Meditation Chamber, SIGGRAPH 2001 Conf. Abstracts and Applications, ACM Press (2001), p. 127.

4. Ellis, P., "The music of sound: a new approach for children with severe and profound and multiple learning difficulties," In: British Journal of Music Education, 14:2 (1997), pp. 173-186.

5. Winkler, T., "Creating Interactive Dance with the Very Nervous System," Proc. of the Connecticut College Symposium on Art and Technology, New London, CT., February 27 - March 2 (1997) pp. 212-217.

6. Gerasimov, V., "Swings That Think," see: http://vadim.www.media.mit.edu/stt/bat.html.

7. Paradiso, J., Hsiao K. Benbasat A., and Teegarden Z., "Design and Implementation of Expressive Footwear," IBM Systems Journal, 39(3\&4), October (2000), pp. 511-529.

8. Morris, S.J. "A Wireless Wearable System for Gait Analysis," Ph.D. thesis, MIT Media Lab and MIT
Health Sciences Technology (HST) Program, April (2004).

9. Benbasat, A.Y., Morris, S.J. and Paradiso, J.A. "A Wireless Modular Sensor Architecture and its Application in On-Shoe Gait Analysis," in the Proc. of the IEEE International Conference on Sensors, Oct. 2124 (2003), pp. 1086-1091.

10. Thaut, M.H., Kenyon, G.P., Schauer, M.L. and McIntosh, G.C. "The Connection Between Rhythmicity and Brain Function," Proc. of IEEE Engineering in Medicine \& Biology, March/April (1999), pp. 101-107.

11. Pachetti, C., Mancini, F., Aglieri, R., Fundaro, C., Martignoni, E. and Nappi, G. "Active Music Therapy in Parkinson's Disease: An Integrative Method for Motor and Emotional Rehabilitation," Psychosomatic Medicine, 62 (2000), pp. 386-393.

12. Asmussen, E., "An Auditory Biofeedback Program for Gait Analysis," Responsive Environments Group Technical Report, MIT Media Lab, August (2003). 